\title{
Upper Critical Solution Temperature Behavior in Poly(vinylidene fluoride)/Poly(methyl methacrylate) Blends ${ }^{\dagger}$
}

\author{
Hiromu SAITO, Yuji FUJITA, ${ }^{*}$ and Takashi INOUE** \\ Department of Textile and Polymeric Materials, \\ Tokyo Institute of Technology, \\ Ookayama, Meguro-ku, Tokyo 152, Japan
}

(Received August 4, 1986)

\begin{abstract}
We investigated the morphological development in poly(vinylidene fluoride)/ poly(methyl methacrylate) blends during the isothermal annealing below melting temperature. At shallow quench depth from the melting point, normal spherulite growth was observed. At deep quench depth, liquid-liquid phase separation took place, resulting in a modulated structure characteristic to spinodal decomposition. There exists a defined boundary between "the shallow" and "the deep" regions in phase diagram. This suggests the existence of upper critical solution temperature (UCST). The UCST behavior was confirmed by dynamic mechanical analysis and Fourier transform infrared spectroscopy.

KEY WORDS Poly(vinylidene fluoride) / Poly(methyl methacrylate) / Blend / UCST / Spherulite / Modulated Structure /
\end{abstract}

Mixtures of poly(vinylidene fluoride) (PVDF) and poly(methyl methacrylate) (PMMA) are known to be molecularly miscible in amorphous state by thermal analysis, ${ }^{1-5}$ dynamic mechanical spectroscopy, ${ }^{2,5}$ dilatometry, ${ }^{2,5}$ small-angle X-ray scattering, ${ }^{6}$ pulsed and ${ }^{13} \mathrm{C}$ NMR, ${ }^{7,8}$ and Fourier transform infrared spectroscopy (FT-IR). ${ }^{9,10}$ The lower critical solution temperature (LCST) is reported to be about $350^{\circ} \mathrm{C}^{11}$ From the homogeneous melt, PVDF crystallizes below melting point. ${ }^{12-16}$

Our preliminary interest had been on the kinetic aspect of crystallization. The kinetic studies by light scattering let us notice that the morphological development during annealing below the melting point was induced not only by the crystallization (liquid-solid phase sepa- ration) but also by a liquid-liquid phase separation. In this paper, we describe the results on the morphological studies by optical microscope and light scattering, suggesting the existence of the upper critical solution temperature (UCST). Results of dynamic mechanical analysis (DMA) and FT-IR are also presented to confirm the UCST behavior.

\section{EXPERIMENTAL}

The polymer specimens used in this study are commercial polymers. PVDF was supplied by Kureha Chemical Industry Co., Ltd.; KF $1100, \bar{M}_{n}=7 \times 10^{4}$. PMMA was supplied by Mitsubishi Rayon Co., Ltd.; Acrypet M001, $\bar{M}_{w}=11.0 \times 10^{4}, \bar{M}_{n}=5.0 \times 10^{4}$.

The PVDF and PMMA were dissolved at

${ }^{\dagger}$ Presented in part at the 34th Annual Meeting of the Society of Polymer Science, Japan, May 1985 [Polym. Prepr., Jpn., 34, 772 (1985)].

* On leave from Corporate Research and Development Laboratory, Tonen Co., Ltd.

** To whom correspondence should be addressed. 
$5 \mathrm{wt} \%$ of total polymer in $N, N$-dimethylacetamide (DMAc). The solution was cast onto a cover glass. The solvent was evaporated under a reduced atmosphere of $10^{-2} \mathrm{mmHg}$ at room temperature. The cast film was further dried under vacuum $\left(10^{-4} \mathrm{mmHg}\right)$ at room temperature for 2 days. The thin film thus prepared ( $c a .15 \mu \mathrm{m}$ thick) was used for FT-IR. In order to prepare a thick film ( $c a$. $30-60 \mu \mathrm{m}$ thick) for light scattering and optical microscopic studies, the film was cast from $10 \mathrm{wt} \%$ solution and dried in the same way as mentioned above. Similar films were also prepared using different solvents such as $N$ methylpyrrolidinone (NMP), dimethyl formamide (DMF), acetone, and methyl ethyl ketone (MEK).

A much more thick film was also prepared by melt mixing for DMA. The polymers were mixed by a mixing extruder (CSI Max Mixing Extruder, CS-194, Custom Scientific Instruments, Inc.) and the extrudate was compression-molded into a sheet of $0.3 \mathrm{~mm}$ thick.

The two-phase structure of the as-cast film was observed under an optical microscope. A light scattering pattern from the as-cast film was obtained by photographic technique similar to that of Stein and Rhodes, ${ }^{17}$ using a $632.8 \mathrm{~nm} \mathrm{He}-\mathrm{Ne}$ laser.

The cast film on cover glass was melted at $200^{\circ} \mathrm{C}$ for $10 \mathrm{~min}$ in a hot chamber. Then the melt specimen was inserted quickly into a hot stage set at a desired lower annealing temperature $T_{\text {ann }}$. Structural development during the isothermal annealing at $T_{\text {ann }}$ was observed under optical microscope and also polarizing microscope (Olympus BH-2).

After annealing for $8 \mathrm{~h}$ at $T_{\text {ann }}$, the specimen was quenched in ice-water bath. The meltannealed-quenched specimen thus prepared was used for DMA, FT-IR, and light scattering studies $\left(H_{\mathrm{v}}\right)$. Dynamic mechanical behavior was measured by Dynamic Mechanical Analyser (DMA Model 980, du Pont) at a heating rate of $2^{\circ} \mathrm{C} / \mathrm{min}$. Resonance frequency and damping were output to a $7470 \mathrm{~A}$ type plotter. Each data corresponds to the dynamic storage modulus $E^{\prime}$ and the dynamic loss modulus $E^{\prime \prime}$, respectively. Fourier transform infra-red spectra was recorded by a FT-IR/3 spectrometer, Japan Spectroscopic Co., Ltd., with $2 \mathrm{~cm}^{-1}$ resolution. Data were stored on FDD-202 floppy disk system and processed for further analysis.

\section{RESULTS AND DISCUSSION}

\section{Morphology in As-Cast Films}

Figure $1 \mathrm{a}$ is an optical micrograph of the ascast film of 30/70 PVDF/PMMA blend from DMAc solution. A highly interconnected twophase morphology with uniform domain size is seen in the micrograph. We call it a "modulated structure" 18 partly for convenience to describe the morphological features of the unique periodicity and the high level of phase connectivity.

Figure $1 \mathrm{~b}$ is a $V_{\mathrm{v}}$ light scattering pattern from the as-cast film of Figure 1a. The ring pattern indicates some degree of regularity of two-phase structure in Figure la. The Bragg spacing from the scattering maximum corresponds to the periodic distance in the micrograph.

Both the high level of phase interconnectivity in micrograph and the light scattering ring showing the unique periodicity are the hallmarks of the spinodal decomposition. The modulated structure seems to originate from the spinodal decomposition during the solution casting process, as described in our recent article, ${ }^{18}$ but not from crystallization. Development of modulated structure was also observed in the other cast films using different solvents, provided that the rate of solvent evaporation was fairly high. When the evaporation rate was slow, a much coarsened and irregular two-phase structure was observed.

Anyway, these results imply that our ternary system, PVDF/PMMA/solvent, is stably a homogeneous solution when the polymer concentration is less than $10 \mathrm{wt} \%$ at least, but it 


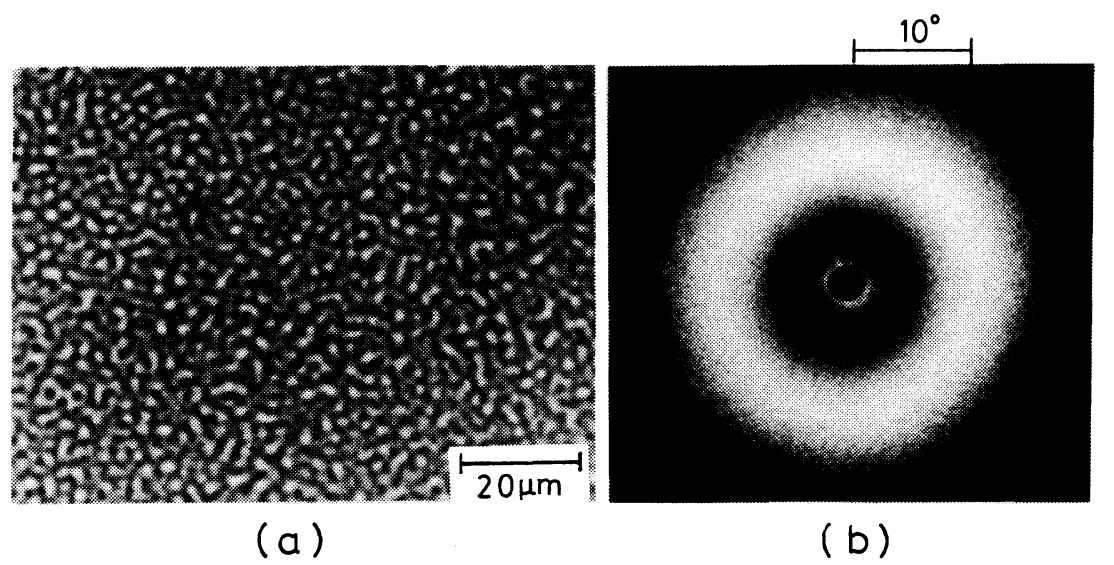

Figure 1. (a) Optical micrograph of 30/70 PVDF/PMMA blend cast from DMAc solution. (b) Light scattering pattern $\left(V_{\mathrm{v}}\right)$ from the blend film.

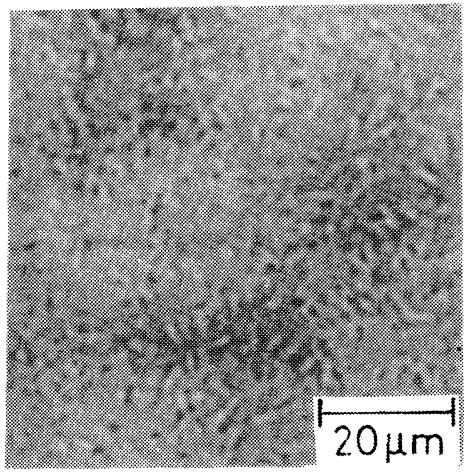

(a) $40 \mathrm{~s}$

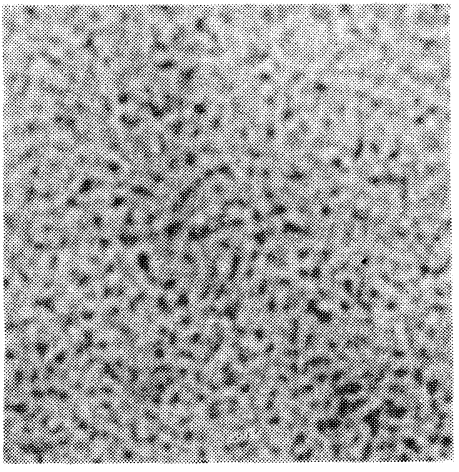

(b) $50 \mathrm{~s}$

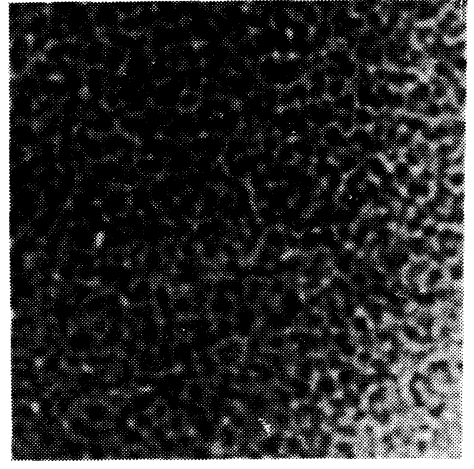

(c) $70 \mathrm{~s}$

Figure 2. Microscopic observation of the structural development in the 60/40 PVDF/PMMA blend during isothermal annealing at $110^{\circ} \mathrm{C}$.

separates into two phases when it is thickened by the solvent evaporation. It suggests a possibility that the instability of concentrated solution resulting in spinodal decomposition comes from the immiscibility between the two polymers at the casting temperature around $22^{\circ} \mathrm{C}$.

\section{Structural Development during Annealing below $T_{\mathrm{m}}$}

When the as-cast film was inserted in the hot chamber set at $200^{\circ} \mathrm{C}$, the modulated structure disappeared within a minute and a transparent melt was obtained. It may correspond to the phase dissolution of the modulated structure by the temperature-jump into the one-phase region. After annealing for $10 \mathrm{~min}$ at $200^{\circ} \mathrm{C}$ and confirming the homogeneity in the melt under optical microscope and by light scattering, the melt specimen was allowed to undergo temperature-drop to $T_{\text {ann }}$.

In Figure 2 is shown a structural development in 60/40 PVDF/PMMA after the temperature-drop from $200^{\circ} \mathrm{C}$ to $T_{\text {ann }}=110^{\circ} \mathrm{C}$. Initially no structure was seen. After $40 \mathrm{~s}$, a modulated structure with low contrast in microscope was detected. The contrast became higher with time of annealing, as demonstrated 


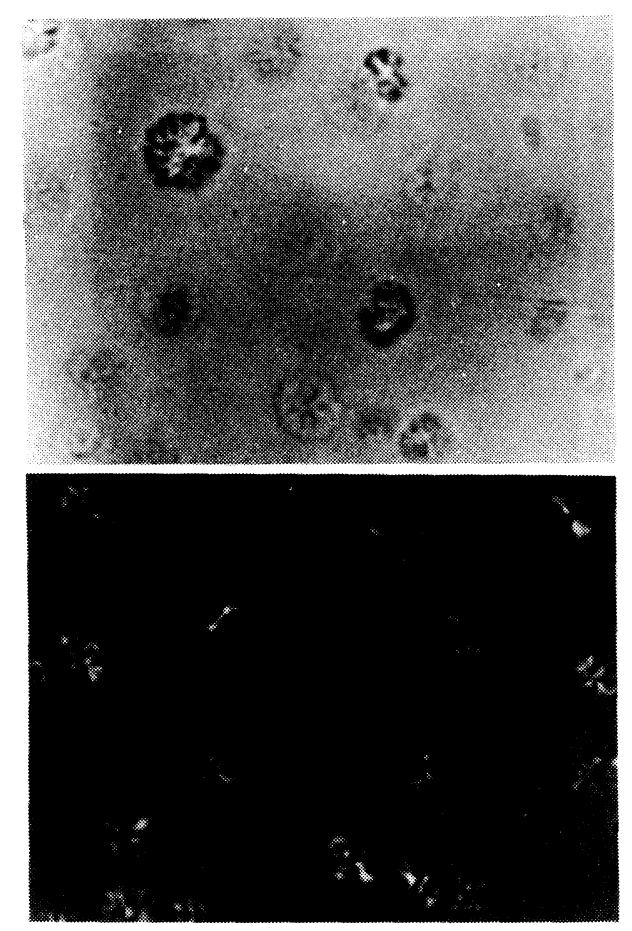

(a) $240 \mathrm{~s}$

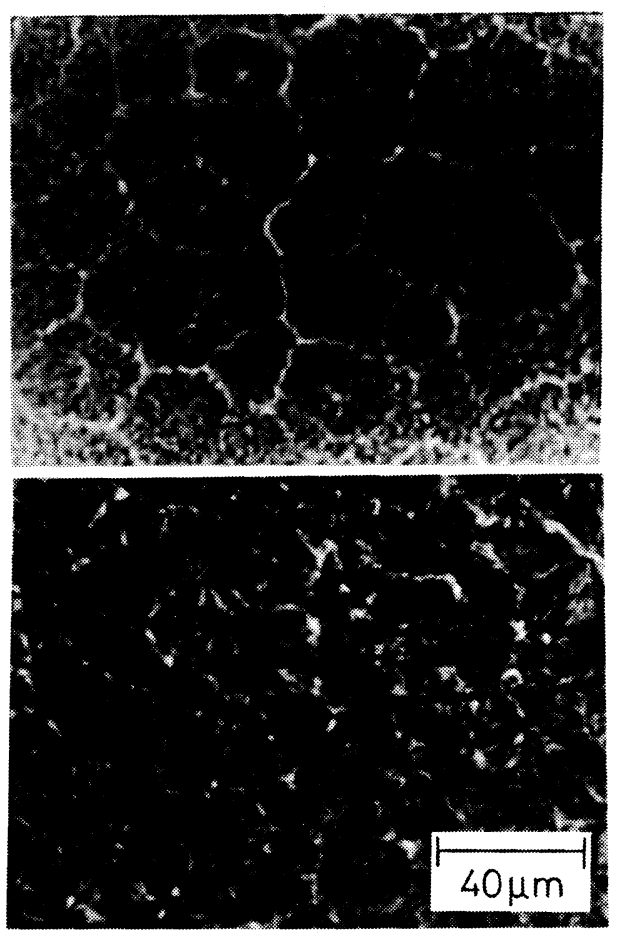

(b) $900 \mathrm{~s}$

Figure 3. Microscopic observation of the structural development in the 60/40 PVDF/PMMA blend during isothermal annealing at $140^{\circ} \mathrm{C}$. Upper, unpolarized; lower, polarized.

by a series of micrographs in Figure 2 .

The modulated structure is similar in appearance to that in Figure 1, but the periodic distance of the structure is much smaller than the original one in the cast film. This implies that the structural memory in the cast film had disappeared by annealing at $200^{\circ} \mathrm{C}$ and a new concentration fluctuation developed in the melt by liquid-liquid phase separation (spinodal decomposition) induced thermally at the $T_{\text {ann }}$. It suggests that UCST (upper critical solution temperature) may locate somewhere above the $T_{\text {ann }}$.

The development of modulated structure was also observed in the blends with different compositions at this $T_{\text {ann }}$ and also at other $T_{\mathrm{ann}}$. This type of behavior is indicated by filled circle in Figure 5. UCST line was drawn somewhat arbitrarily between the filled circle region and the open circle region, mentioned later.

The modulated structure in Figure 2 changed to be more coarsened with time of further annealing. At this later stage, one phase in the modulated structure began to brighten under polarizing microscope, indicating the formation of small spherulites in the PVDF rich phase.

When the $T_{\text {ann }}$ was higher, a completely different morphology was observed as shown in Figure 3. Optical micrographs in Figure 3 were taken for the 60/40 PVDF/PMMA after the temperature-drop from $200^{\circ} \mathrm{C}$ to $T_{\text {ann }}=$ $140^{\circ} \mathrm{C}$. These are nothing but the indication of the familiar spherulite growth; sheaf-like structure located at random in early stage, formation of spherulites, and truncation in the well-developed spherulites at late stage. That is, the liquid-solid phase separation (crystallization) takes place at this high $T_{\text {ann }}$, in other 


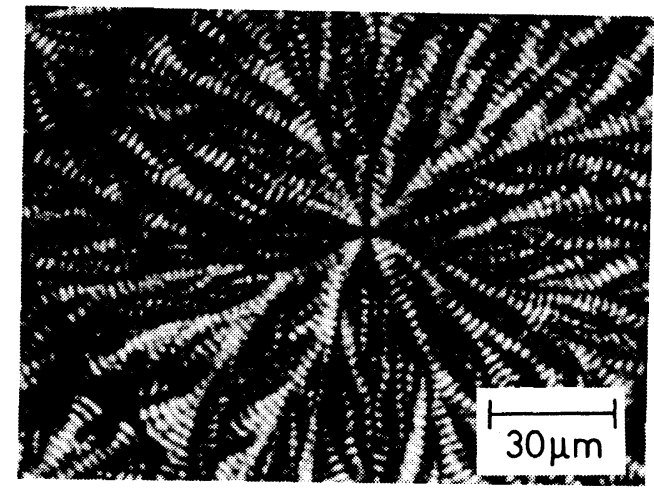

(a)


Figure 4. Polarized micrograph and light scattering patterns $\left(H_{\mathrm{v}}\right)$ of the $60 / 40$ PVDF/PMMA blend annealed at $150^{\circ} \mathrm{C}$ for $5 \mathrm{~h}$. (a) Open spherulite texture under microscope. (b) Schematic illustration of complex $H_{\mathrm{v}}$ scattering pattern from (c) and (d). (c) $H_{\mathrm{v}}$ scattering pattern; small angle view, (d) wide angle view.

words, at the shallow quench depth from melting point. The spherulite growth was also observed in the blends with different compositions at various shallow quenches. This behavior is indicated by open circle in Figure 5.

When the quench depth was very shallow, we observed an opened spherulite, exhibiting complex $H_{\mathrm{v}}$ light scattering pattern, as typically shown in Figure 4 . Of course, this spherulite is believed to be formed on the same line as in Figure 3. But it may come from the disordering in lamella growth, probably due to the kinetic reason as discussed by Morra and Stein. ${ }^{14,15}$

\section{LCST Behavior}

As mentioned before, Paul et al. ${ }^{11}$ have suggested the existence of LCST (lower critical solution temperature) in PVDF/PMMA. The LCST behavior was confirmed in our system by cloud point method as follows. The melt specimen $\left(200^{\circ} \mathrm{C}\right)$ underwent a rapid temperature-jump to an isothermal setting of higher temperature above $300^{\circ} \mathrm{C}$. When no appreciable change in transparency took place, we judged that the system was still in the single-phase region. This is indicated by cross. in Figure 5. When the melt became opaque, we judged that the system was in the two-phase region. This is indicated by triangle in Figure 


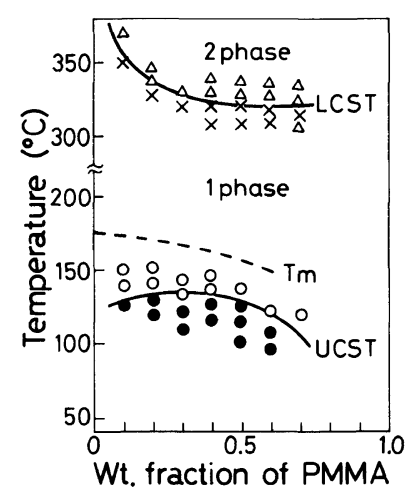

Figure 5. Phase diagram of PVDF/PMMA. Melting point depression curve is drawn by broken line, based on literature data. ${ }^{3}$, development of modulated structure; $\bigcirc$, spherulite growth; $\triangle$, opaque; $\times$, transparent.

5. (Above LCST, the melt became opaque in less than $10 \mathrm{~s}$ after the temperature-jump.) On the basis of these observations, the LCST line is drawn between the crosses and triangles.

Thus we have found the coexistence of the LCST and UCST in the PVDF/PMMA system. Of particular interest is the existence of UCST. The existence of UCST has been known for a couple of polymer blends including random copolymer; copolymer/homopolymer and copolymer A/copolymer B, both with high molecular weights. ${ }^{19,20}$ To our knowledge, the present observation is the first one in homopolymer/homopolymer systems with high molecular weights. In order to conclude so, we have to give more careful consideration on it with the aid of other investigations, in terms of molecular motions and spectroscopy, as will be described below.

\section{Dynamic Mechanical and Optical Spectros- copies}

In Figure 6 are shown typical dynamic mechanical properties of PVDF/PMMA blends annealed above and below the UCST. Figure $6 \mathrm{a}$ is for the blend annealed at $110^{\circ} \mathrm{C}$ (below UCST) for $8 \mathrm{~h}$. Referring to the previous investigations, ${ }^{2,5}$ we may assign the $-40^{\circ} \mathrm{C}$ peak to the $\beta$-transition (glass transition) of PVDF, the $70^{\circ} \mathrm{C}$ peak to the $\alpha$ -

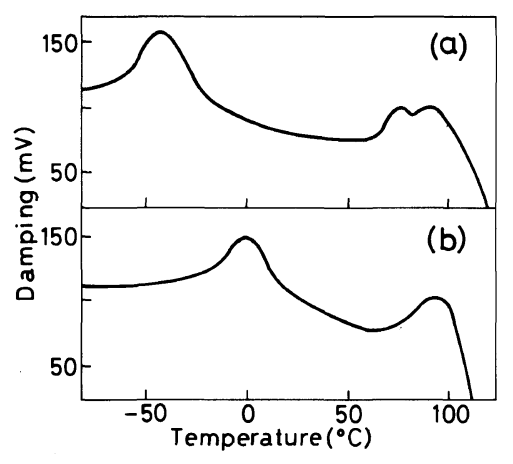

Figure 6. Dynamic mechanical spectrum of the 70/30 PVDF/PMMA annealed at (a) $135^{\circ} \mathrm{C}$ and (b) $150^{\circ} \mathrm{C}$, respectively.

transition associated with the molecular motion in crystalline region of PVDF, and the $90^{\circ} \mathrm{C}$ peak to the glass transition of PMMA, respectively. It means that the annealed blend is composed of pure PVDF and pure PMMA phases. That is, almost complete phaseseparation into individual polymer phases took place during the long annealing at $110^{\circ} \mathrm{C}$, below the UCST.

On the other hand, for the blend annealed above UCST, we hardly see the peak at the $\beta$ transition temperature of PVDF, but a transition peak around $0^{\circ} \mathrm{C}$, as shown in the Figure $6 \mathrm{~b}$. It is reasonable to assign the $0^{\circ} \mathrm{C}$ peak to the glass transition of amorphous region composed of homogeneous mixture of PVDF and PMMA. The $90^{\circ} \mathrm{C}$ peak is assumed to be the $\alpha$ transition of PVDF shifted to higher temperature. The results support the morphology formed by the crystallization from single phase melt.

Thus, there exists a basic difference between the upper and the lower figures in Figure 6. We also observed the difference in the $70 / 30$ blends annealed at various $T_{\text {ann }}$. The difference is also observed in the blends with different compositions. The boundary between the "upper" and "lower" type behavior located at $T_{\text {ann }}=$ $137^{\circ} \mathrm{C}$. This boundary temperature locates on the UCST line in Figure 5. Thus the dynamic mechanical analysis confirm the existence of 


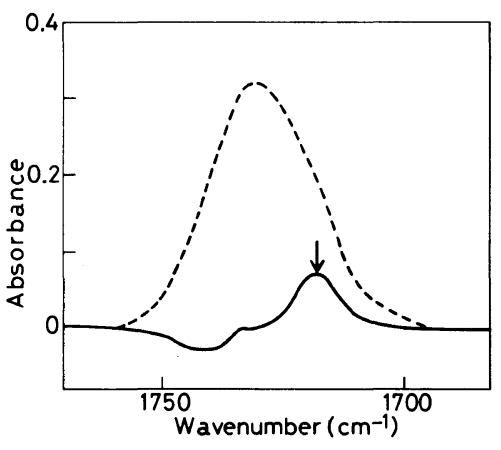

Figure 7. FT-IR spectra covering the $\mathrm{C}=\mathrm{O}$ stretching frequency range. Broken line, observed spectrum of the $60 / 40 \mathrm{PVDF} / \mathrm{PMMA}$ annealed at $150^{\circ} \mathrm{C}$ for $8 \mathrm{~h}$; solid line, difference spectrum.

\section{UCST.}

The whole FT-IR spectrum of PVDF/ PMMA blend did not show a dramatic deviation from the additive spectrum of the component polymers. However, a small but distinct deviation was observed in the $\mathrm{C}=\mathrm{O}$ stretching frequency region around $1730 \mathrm{~cm}^{-1}$, as pointed out by Coleman et al..$^{9}$ This is the reason why the spectrum is presented in a limited range of $1650-1800 \mathrm{~cm}^{-1}$ in Figure 7. In order to clarify the deviation, digital absorbance subtraction technique was employed. Solid line in Figure 7 is the difference spectrum obtained by subtracting the PMMA spectrum from that of the blend.

It can be seen that complete subtraction of this band is not possible, owing to the band broadening at low frequency region and the band narrowing at high frequency region. It indicates the specific interaction of carbonyl group in the blend. It is expected that the intensity of the peak in difference spectrum (pointed by arrow) is high when the specific interaction is strong. So, as a measure of interaction strength, we employed the absorbance ratio of this peak in difference spectrum at $1718 \mathrm{~cm}^{-1}$ to that in the observed spectrum at $1730 \mathrm{~cm}^{-1}$.

In Figure 8 the absorbance ratio is shown as a function of the $T_{\text {ann }}$. As expected, the specific interaction is weak in the blends annealed at

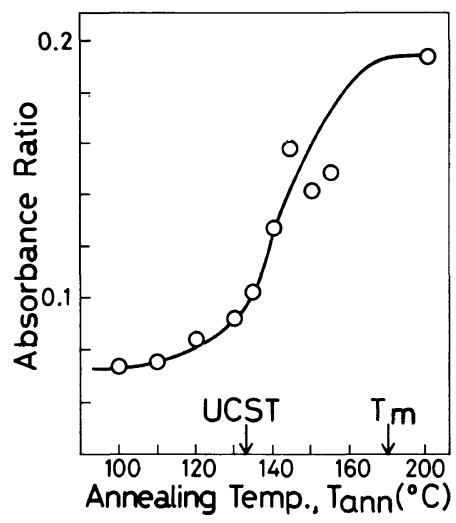

Figure 8. Absorbance ratio, a measure of strength in specific interaction, as a function of annealing temperature. 60/40 PVDF/PMMA.
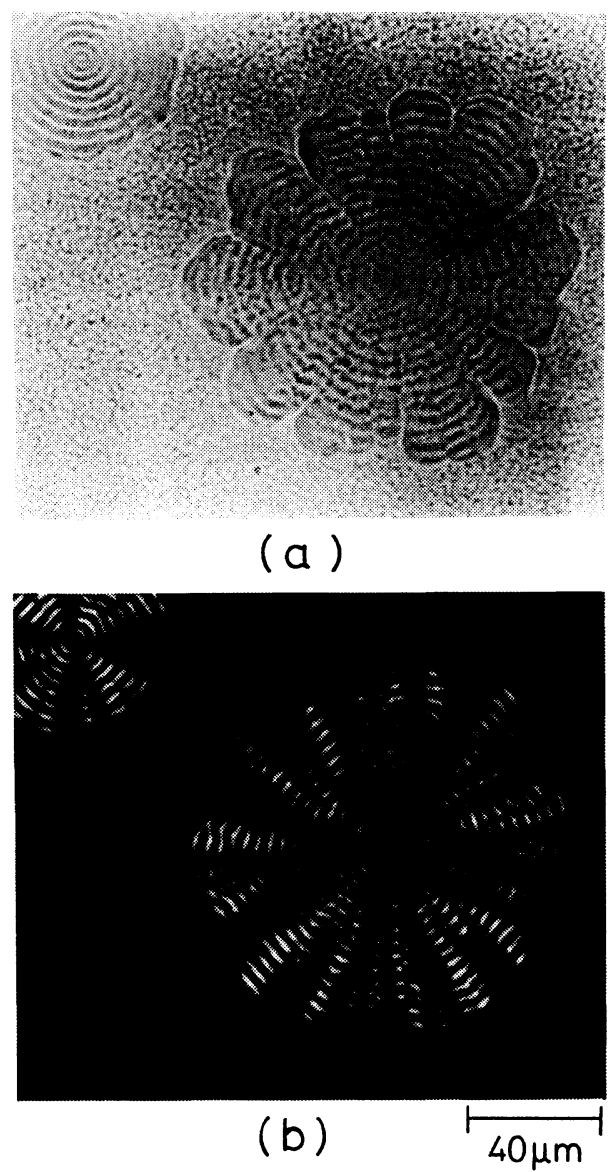

Figure 9. Micrograph of 50/50 PVDF/PMMA blend annealed in two steps: first, at $155^{\circ} \mathrm{C}$ for $48 \mathrm{~h}$; second, at $120^{\circ} \mathrm{C}$ for $48 \mathrm{~h}$. (a) unpolarized and (b) polarized. 
low temperatures. It should be due to the phase separation below the UCST. On the other hand, the interaction is strong in the blends prepared by the shallow quenches, implying the single-phase nature in amorphous region. The increase of absorbance ratio with $T_{\text {ann }}$ is remarkable above the UCST. Thus, implication from FT-IR observation is on the same line of the understanding on the phase behavior by the microscopic and DMA studies.

\section{A Structure Developed by Two-Step Annealing}

If the melt blend undergoes the first temperature-drop to a $T_{\text {ann }}$ above UCST and isothermal annealing at this $T_{\text {ann }}$ for a certain time ("the first annealing"), and then the second temperature-drop to another $T_{\text {ann }}$ below UCST and isothermal annealing ("the second annealing"), the spherulite growth is expected at the first annealing and the residual melt is expected to be converted to the modulated structure by liquid-liquid phase separation by the second annealing, resulting in a complex morphology in which the spherulites are dispersed in a matrix having the modulated structure. Actually, we observed this morphology as shown in Figure 9. This is an additional confirmation of the phase behavior.

\section{CONCLUDING REMARKS}

Thus the UCST behavior was suggested in our PVDF/PMMA system. The location of UCST curve in Figure 5 was determined by the kinetic studies. ${ }^{21}$ It does not necessarily correspond to that in an equilibrium sense. The equilibrium UCST curve may locate at a temperature region higher than that in Figure 5.

It is hard to interpret the existence of UCST in the framework of current theory of polymer-polymer miscibility. ${ }^{22}$ One of the interpretation in terms of order-to-disorder transition, however, will be presented in a forthcoming paper.
Acknowledgement. We acknowledge the partial support by a Grant-in-Aid for Scientific Research (No. 60470103) from the Ministry of Education, Science, and Culture of Japan.

\section{REFERENCES AND NOTES}

1. J. S. Noland, N.-C. Hsu, R. Saxon, and J. M. Schmitt, Adv. Chem. Ser., 99, 15 (1971).

2. D. R. Paul and J. O. Altamirano, Adv. Chem. Ser., 142, 371 (1975).

3. T. Nishi and T. T. Wang, Macromolecules, 8, 909 (1975).

4. E. Roerdink and G. Challa, Polymer, 19, 173 (1978).

5. Y. Hirata and T. Kotaka, Polym. J., 13, 273 (1981).

6. J. H. Wendorff, J. Polym. Sci., Polym. Lett. Ed., 18, 439 (1980).

7. D. C. Douglass and V. J. McBrierty, Macromolecules, 11, 766 (1978).

8. T. C. Ward and T. S. Lin, Adv. Chem. Ser., 206, 59 (1984).

9. M. M. Coleman, J. Zarian, D. F. Varnell, and P. C. Painter, J. Polym. Sci., Polym. Lett. Ed., 15, 745 (1977).

10. E. Roerdink and G. Challa, Polymer, 21, 509 (1980).

11. R. E. Bernstein, C. A. Cruz, D. R. Paul, and J. W. Barlow, Macromolecules, 10, 681 (1977).

12. T. T. Wang and T. Nishi, Macromolecules, 10, 421 (1977).

13. B. S. Morra and R. S. Stein, J. Polym. Sci., Polym. Phys. Ed., 20, 2243 (1982).

14. B. S. Morra and R. S. Stein, J. Polym. Sci., Polym. Phys. Ed., 20, 2261 (1982).

15. B. S. Morra and R. S. Stein, Polym. Eng. Sci., 24, 311 (1984).

16. C. Leonard, J. L. Halary, L. Monnerie, D. Broussoux, B. Servet, and F. Micheron, Polym. Commun., 24, 110 (1983).

17. R. S. Stein and M. B. Rhodes, J. Appl. Phys., 31, 1873 (1960).

18. T. Inoue, T. Ougizawa, O. Yasuda, and $\mathrm{K}$. Miyasaka, Macromolecules, 18, 57 (1985).

19. T. Ougizawa, T. Inoue, and H. W. Kammer, Macromolecules, 18, 2089 (1985).

20. T. Ougizawa and T. Inoue, Polym. J., 18, 521 (1986).

21. We believe that the UCST behavior was detected though a "temperature window" in which the rate of spinodal decomposition prevails over that of crystallization.

22. O. Olabisi, L. M. Robeson, and M. T. Shaw, "Polymer-Polymer Miscibility," Academic Press, New York, N. Y., 1979. 